ISSN : $2620-4665$ (print)

ISSN : 2620 - 4673 (online)

Website : http://jurnal.untan.ac.id/index.php/JPLP2KM

\title{
KEGIATAN PROGRAM KEMITRAAN MASYARAKAT DI SD MUHAMAMDIYAH PANDES BANTUL DENGAN KEGIATAN PENGHIJAUAN LINGKUNGAN SEKOLAH
}

\author{
Hadi Prsetyo Suseno', Suraya², Erfanti Fakiyah ${ }^{3}$ \\ ${ }^{1}$ Teknik Lingkungan, Fakultas Sains Terapan \\ 2;3 Teknik Informatika, Fakultas Teknologi Industri \\ Institut Sains \& Teknologi AKPRIND Yogyakarta \\ email: hp_suseno@akprind.ac.id
}

\begin{abstract}
This paper examines the implementation of the community partnership program activities of the IST AKPRIND team in SD Muhammadiyah Pandes. One of the PKM activities is the greening program of the school environment. This goal is an effort to create an environmentally sound school. Current environmental issues are a serious problem that must be realized and must be delivered from the beginning to the younger generation, especially elementary students. A clean school environment is one element that must be developed and maintained continuously. In order for a comfortable education process it needs to be balanced with a healthy and clean environment. The implementation of PKM activities begins with a comparative study to partner locations and conducts surveys on school environment issues and the needs needed by schools, especially regarding environmental greening activities. PKM activities include reforesting the school environment as well as socializing the importance of a healthy environment and environmental issues for elementary school students. Activities involving students were provided with assistance in introducing environmental activities such as with coloring competitions with themes for students in grades 1 and 2, class hygiene competitions, installation of environment-themed posters. The results of the PkM activities are expected to make the school atmosphere more beautiful and students better understand the importance of cleanliness and maintenance of a beautiful and healthy school environment.
\end{abstract}

Keywords: Environment, school, greening, students

\section{PENDAHULUAN}

Lingkungan sekolah disamping sebagai tempat untuk mendidik anak dengan pengetahuan, juga berkewajiban untuk mendidik siswa dari sisi karakter dan kepedulian pada lingkungan. Lingkungan sekolah yang hijau dan asri tentu nya akan menambah suasana belajar yang menyenangkan. Penghijauan dapat dilakukan apabila ada kemauan dari masing-masing individu. Oleh Karena itu agar lingkungan sekolah menjadi lebih asri dan sehat, guru dan siswa perlu menjaga lingkungan sekitar sekolah. Program penghijauan di sekolah dapat diterapkan oleh para guru dan para siswa. Tugas para guru diantaranya menjelaskan kepada para siswa dampak positif dan negatif nya apabila melakukan penghijauan. Serta mengajak siswa melakukan penghijauan 
dengan hal-hal yang menarik, Misal melakukan acara penanaman tanaman yang hijau dan rindang di sekolah. Bentuk lain dari menanamkan kepedulian pada para siswa adalah dengan melakukan perawatan kelas dan kewajiban merawat tanaman di depan kelas.

Tingkat satuan pendidikan yang dianggap sebagai dasar pendidikan adalah sekolah dasar. Di sekolah inilah anak didik mengalami proses pendidikan dan pembelajaran. Dan secara umum pengertian sekolah dasar dapat kita katakan sebagai institusi pendidikan yang menyelenggarakan proses pendidikan dasar dan mendasari proses pendidikan selanjutnya. Pendidikan ini diselenggarakan untuk anak-anak yang telah berusia tujuh tahun dengan asumsi bahwa anak seusia tersebut mempunyai tingkat pemahaman dan kebutuhan pendidikan yang sesuai dengan dirinya. Lingkungan sekolah merupakan bagian dari kehidupan yang tidak terpisahkan, apa lagi generasi penerus bangsa seperti kita bergantung pada kegiatan akademik di sekolah. Karenanya, menjaga nya agar tetap bersih dan sehat sangat penting untuk dilakukan.

Menciptakan lingkungan sekolah yang bersih dan sehat bisa diwujudkan asalkan dengan partisipasi seluruh warga sekolah serta dukungan dari jajaran internal sekolah. Karenanya, penting untuk menciptakan lingkungan yang sehat dan bisa membangun Indonesia dengan semangat kebersihan lingkungan yang dilakukan sejak usia dini. Kesadaran akan pentingnya pemeliharaan lingkungan harus dilakukan sejak dini pada setiap orang. Di era meningkat nya polusi dan penggunaan berbagai bahan yang dapat merusak alam, kesadaran cinta lingkungan sangat penting ditanamkan sejak dini. Penurunan kualitas lingkungan terjadi karena kelalaian, ketidaktahuan dan tiadanya etika serta/moral terhadap lingkungan. Pendidikan Lingkungan Hidup penting diajarkan pada murid SD, untuk memperoleh pengetahuan, kesadaran dan mempunyai sikap dan perilaku peduli lingkungan.(Muslicha 2016)

Menciptakan kondisi yang baik bagi sekolah untuk menjadi tempat pembelajaran dan penyadaran warga sekolah, sehingga di kemudian hari warga sekolah tersebut dapat turut bertanggung jawab dalam upaya-upaya penyelamatan lingkungan hidup dan pembangunan berkelanjutan. Kegiatan utama diarahkan pada terwujud nya kelembagaan sekolah yang peduli dan berbudaya lingkungan bagi sekolah dasar dan menengah di Indonesia. Disamping pengembangan norma-norma dasar yang antara lain: kebersamaan, keterbukaan, kesetaraan, kejujuran, keadilan, dan kelestarian fungsi lingkungan hidup dan sumber daya alam. Serta penerapan prinsip dasar yaitu: partisipatif, dimana komunitas sekolah terlibat dalam manajemen sekolah yang meliputi keseluruhan proses perencanaan, pelaksanaan dan evaluasi sesuai 
ISSN : $2620-4665$ (print)

ISSN : 2620 - 4673 (online)

Website : http://jurnal.untan.ac.id/index.php/JPLP2KM

tanggung jawab dan peran; serta berkelanjutan, dimana seluruh kegiatan harus dilakukan secara terencana dan terus menerus secara komprehensif. (Pantiwati 2015)

Agar pelajaran mengenai lingkungan hidup yang diberikan guru dapat dipahami siswa, kondisi sekolah haruslah nyaman dan bersih sesuai dengan materi yang disampaikan. Lingkungan sekolah yang bersih, nyaman dan sehat tentu nya membuat suasana sekolah yang nyaman. Kebersihan sekolah harus menjadi prioritas dan selalu harus dilakukan kontrol terhadap kebersihan sekolah/ kelas serta suasana lingkungan yang nyaman juga harus menjadi prioritas. . Sekolah yang kotor akan membuat kegiatan belajar terganggu dan menjadi sarang penyakit bagi seluruh warga sekolah. Peranan siswa dalam arti kata sikap, perilaku, pengetahuan dan keikutsertaan nya dalam permasalahan lingkungan perlu dibina dan dikembangkan, sebab siswa mempunyai peranan penting dalam menciptakan lingkungan yang bersih dan sehat. Pengetahuan kebersihan lingkungan merupakan awal pertama siswa untuk menciptakan lingkungan yang bersih.

Di sisi lain, masyarakat disekitar kita ternyata juga belum berperilaku baik pada lingkungan. Pedagang kaki lima masih berperilaku jorok. Banyak pedagang yang tampak dari depan sudah mandi dan rapi. Akan tetapi ketika dilihat di belakangnya, ternyata mereka membuang sampah secara sembarangan. Kebersihan lingkungan dapat diwujudkan dengan melaksanakan program $3 R$, yaitu Reuse (memanfaatkan kembali), Reduce (mengurangi), Recycle (mendaur ulang). Pelaksanaan program $3 R$ harus didahului dengan perilaku membuang sampah secara benar, yaitu membuang sampah di tempat yang telah disediakan. (Utaya; Sugeng 2009).

Penelitian yang terkait dengan kegiatan pendidikan lingkungan pada siswa SD sudah dilakukan di beberapa sekolah dasar, diantara nya Jupri (Jufri; Jumarddin La Fua; Ratna Umi Nurlila 2018), menyimpulkan pendidikan lingkungan yang dilakukan Sekolah Dasar Negeri 1 Baruga telah dilaksanakan untuk membentuk karakter peduli lingkungan. Bentuk kegiatan atau program yang dilakukan meliputi integrasi dalam kegiatan pembelajaran melalui pendekatan tematik, program- program ekstrakurikuler yang berbasis pengelolaan lingkungan dan sosialisasi pendidikan lingkungan melalui pesan-pesan teks yang disampaikan kepada siswa yang menegaskan tentang kewajiban untuk memelihara dan menjaga lingkungan.

Kegiatan dan upaya untuk menanamkan sejak terhadap kepedulian siswa SD sudah dilakukan di beberapa sekolah dasar (Fauzzia et al. 2018) dan (Ipin 2017). Penyampaian materi lingkungan hidup ke para siswa dapat dilakukan dengan memberikan sosialisasi (Wicaksono 2018) dan (Mardiani 2017) serta mengintegrasikan pendidikan lingkungan hidup dalam kurikulum. 
(Samri 2016) dan (Rezkita and Wardani 2018). Pentingnya penanaman lingkungan hidup harus dilakukan semenjak usia dini, lingkungan masyarakat mempunyai pengaruh penting terhadap proses belajar anak. Karena sebagian besar waktu anak berada dalam lingkup keluarga dan masyarakat. Untuk itu menjadi sebuah keniscayaan masyarakat ikut berpartisipasi dalam pendidikan baik secara langsung maupun tidak langsung (Choiri 2019).

\section{METODE}

\subsection{Khalayak Sasaran}

Sasaran kegiatan program kemitraan masyarakat adalah siswa dan penghijauan lingkungan dengan melakukan penanaman pohon. Kegiatan pada siswa dititik beratkan dengan kegiatan sosialisasi pada siswa dan kegiatan penanaman pohon, penyediaan tempat sampah serta pemasangan poster yang bertemakan lingkungan. Fokus kegiatan yang terkait dengan siswa dilakukan dengan kegiatan pendampingan siswa di kelas, lomba mewarnai untuk siswa kelas 1 dan 2 serta lomba kebersihan kelas untuk kelas 3-6.

\subsection{Metode Kegiatan}

Metode kegiatan dilakukan dengan diawali berkomunikasi dengan Kepala Sekolah mengenai kegiatan PkM terutama yang bertemakan lingkungan dan kegiatan yang akan dilakukan serta jadwal yang direncanakan. Tahapan implementasi kegiatan dilakukan dengan penanaman pohon di area lapangan olah raga, tanaman perindang dalam pot besar, tanaman gantung di area parkir sepeda serta pemasangan poster bertemakan lingkungan di kelas. Kegiatan yang melibatkan siswa dilakukan dengan sosialisasi di kelas mengenai pentingnya memelihara lingkungan hidup, lomba berwarnai dengan tema lingkungan hidup dan lomba kebersihan kelas. Diakhir kegiatan dilakukan evaluasi dan pembuatan laporan. Diagram kegiatan PkM dijelaskan dalam gambar 1. 
ISSN : $2620-4665$ (print)

ISSN : $2620-4673$ (online)

Website : http://jurnal.untan.ac.id/index.php/JPLP2KM

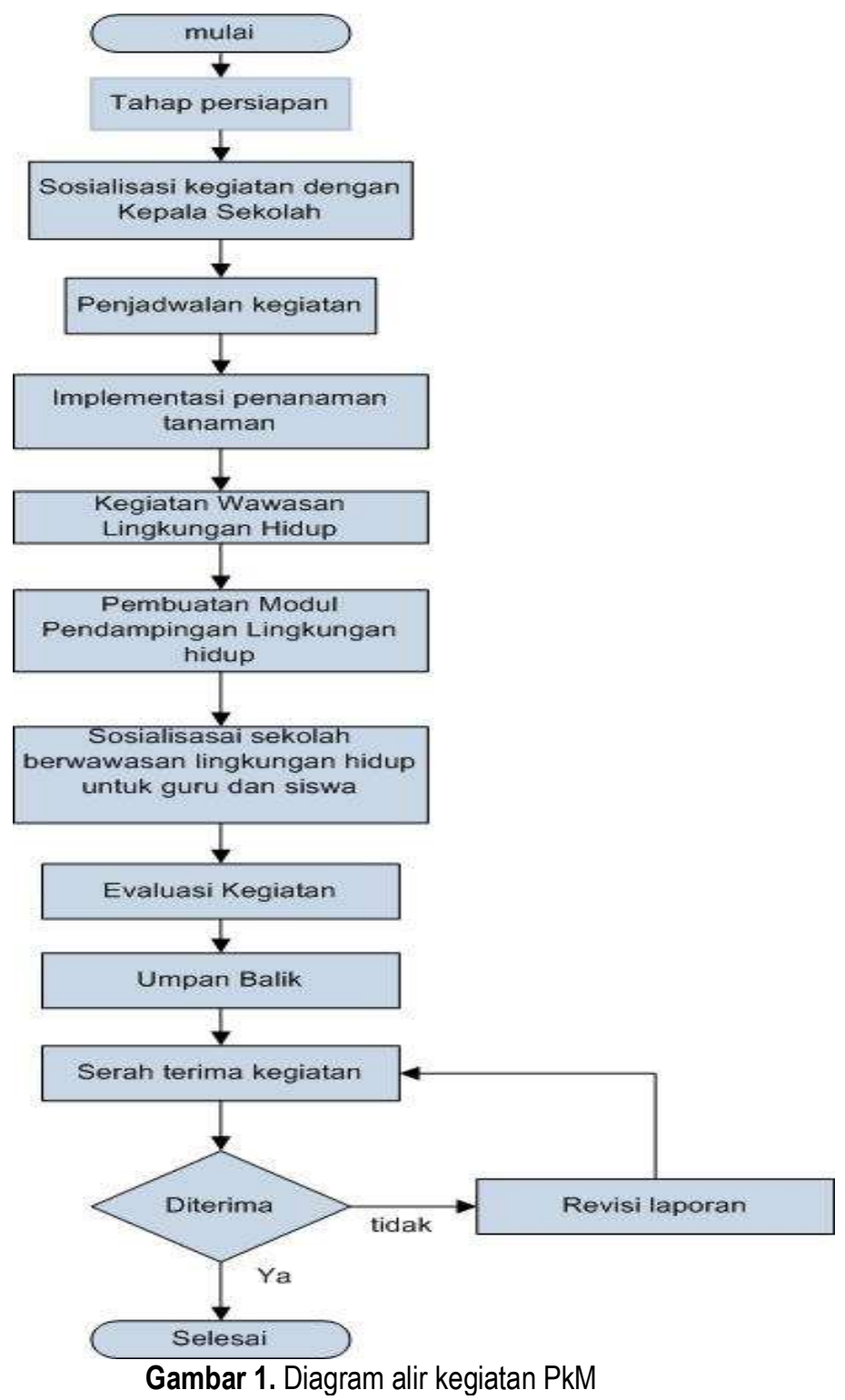

\section{HASIL DAN PEMBAHASAN}

\subsection{Integrasi Pendidikan Lingkungan Alam Pada Mata Pelajaran}

Upaya menanamkan kepedulian siswa sejak dini dapat dilakukan dengan kegiatan ekstrakurikuler dan mengintegrasikan pendidikan lingkungan hdiup dalam mata pelajaran. Pendidikan mengenai lingkungan hidup merupakan usaha menanamkan kesadaran sejak dini kepada siswa terutama mengenai pelestarian lingkungan hidup melalui proses pembelajaran di sekolah. Pendidikan lingkungan hidup merupakan suatu bidang ilmu yang harus sedini mungkin dipelajari di sekolah dasar dengan cara pengintergrasian pengetahuan 
lingkungan hidup kedalam disiliplin ilmu lainnya. Beberapa buku pengenalan lingkungan hidup diantaranya:

- Mengenal Lingkungan Sekitar Jilid 3. Buku Mengenal Lingkungan Sekitar merupakan buku teks pelajaran IImu Pengetahuan Sosial. Buku ini memiliki tema yang mencakup materi pembelajaran khususnya pengenalan lingkungan, tema 1 tentang Lingkungan Alam dan Lingkungan Buatan.(Nurhadi 2009). Kover buku Mengenal Lingkungan Sekitar ada pada gambar 2

- Lingkungan Sahabat Kita,dalam buku ini mengupas tentang manusia dan lingkungan, perubahan lingkungan, usaha pelestarian lingkungan (Heny Kusumawati 2017). Kover buku Lingkungan Sahabat Kita ada pada gambar 2.
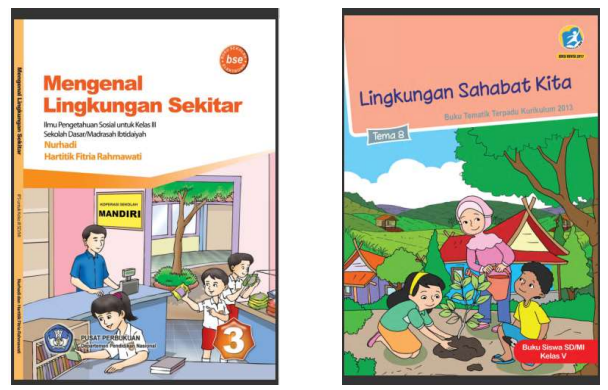

Gambar 2. Buku Lingkungan Hidup untuk siswa SD

\subsection{Kegiatan Pelaksanaan PkM}

Pelaksanaan kegiatan PkM dengan tema lingkungan hidup dilaksanakana dengan beberapa kegiatan, yaitu

1. Kegiatan penanaman pohon perindang di lapangan olahraga

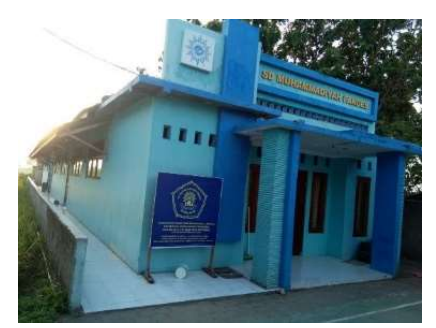

(a) Sebelum adanya penanaman

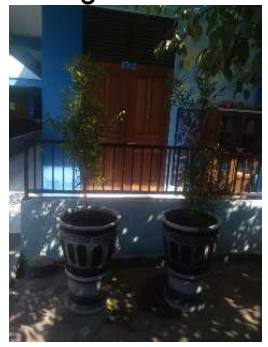

(b) Penanaman pohon di depan ruang kantor

Gambar 3. Penanamana pohon di depan ruang kantor 
ISSN : $2620-4665$ (print)

ISSN : 2620 - 4673 (online)

Website : http://jurnal.untan.ac.id/index.php/JPLP2KM

2. Kegiatan penyediaan tempat sampah organik dan an organik

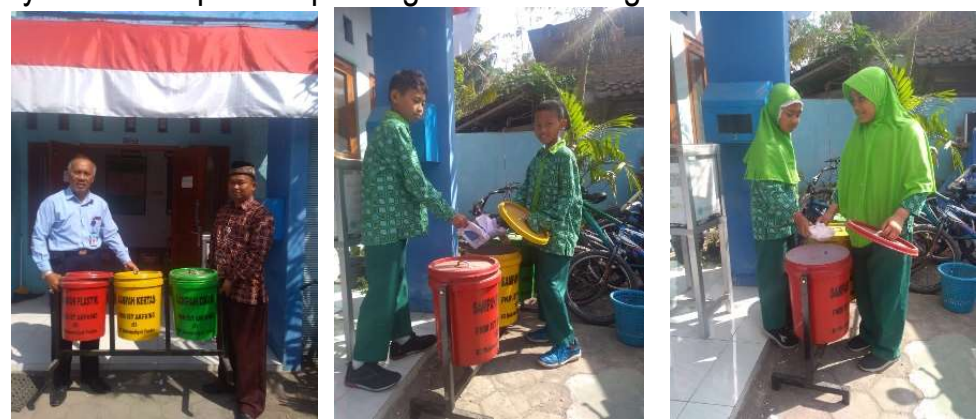

Gambar 4. Tempat Sampah dan proses sosialisasi ke siswa

3. Kegiatan penanaman tanaman dalam pot disekitar ruang kelas dan ruang kantor

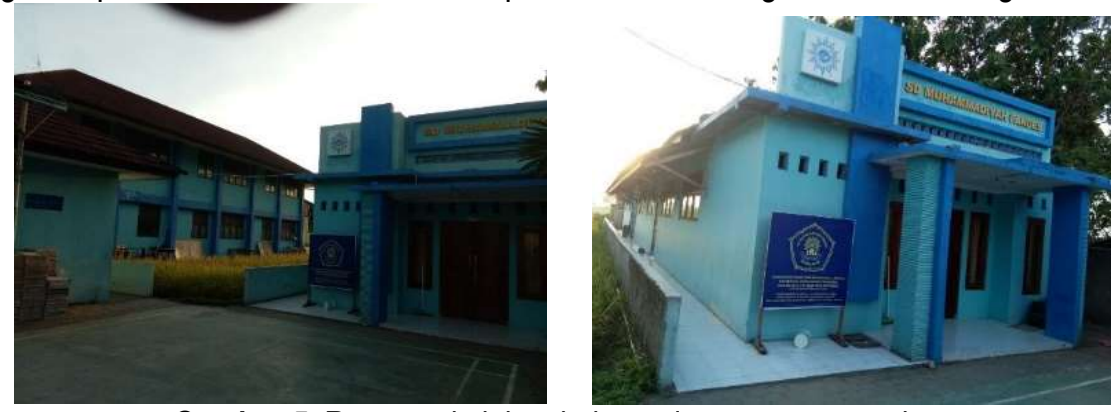

Gambar 5. Ruang sekolah sebelum ada penanaman pohon
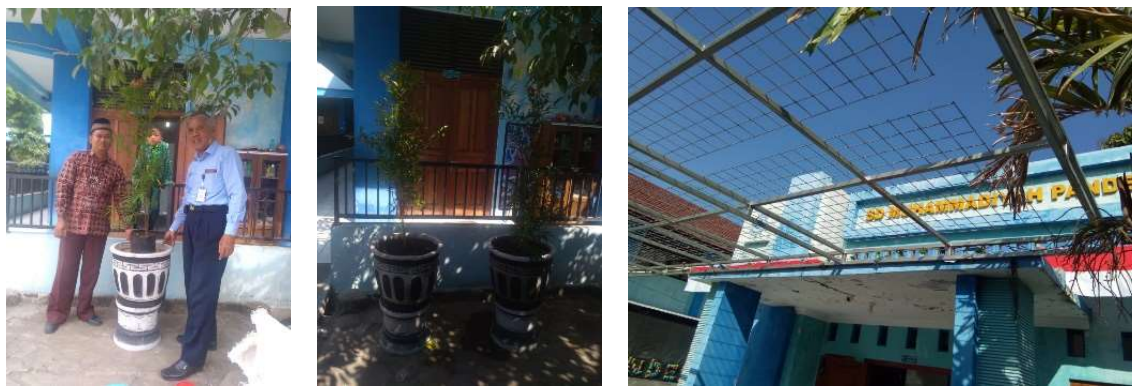

Gambar 6. Penanamana pohon di depan ruang kantor

4. Pembuatan dan pemasangan poster bertemakan lingkungan hidup yang di pasang di dalam kelas
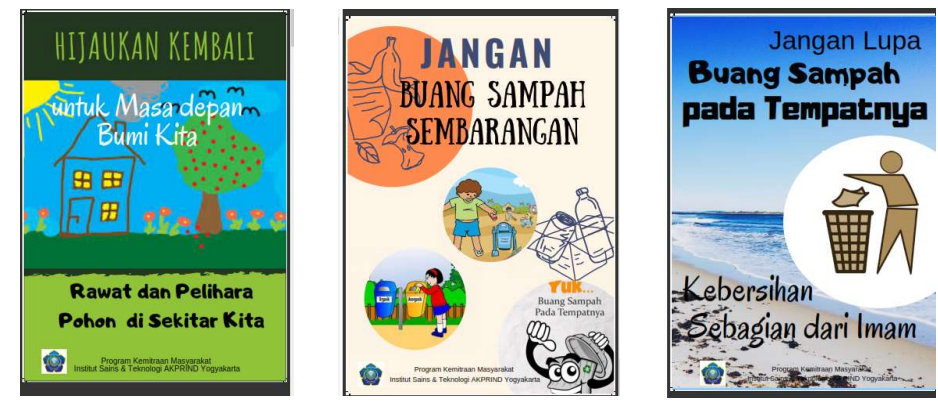

Gambar 7. Poster yang dipasang di kelas 


\section{SIMPULAN DAN REKOMENDASI}

Kegiatan PkM yang dilaksanakan di SD Muhammadiyah Pandes memberikan dampak positif pada kegiatan di sekolah, Kegiatan PKM dengan tema lingkungan hidup disamping dilakukan dengan aktivitas penghijauan lingkungan sekolah juga memberikan pendampingan kepada siswa akan pentingnya perawat lingkungan hidup. Penanaman peduli pada lingkungan hidup harus ditanamkan sejak usia dini dan dapat dilakukan melalui materi pembelajaran, poster/slogan dan kegiatan langsung yang berinteraksi dengan siswa.

\section{UCAPAN TERIMA KASIH}

Penulis mengucapkan terima kasih kepada Direktorat Riset dan Pengabdian pada Masyarakat Direktorat Jenderal Riset dan Pengembangan Kementerian Riset, Teknologi dan Pendidikan Tinggi yang telah memberi dukungan dana untuk kegiatan Pengabdian kepada masyarakat pada skema Program Kemitraan Masyarakat (PKM) tahun pendanaan 2019.

\section{DAFTAR PUSTAKA}

Choiri, Moh. Miftahul. 2019. "Upaya Pemanfaatan Lingkungan Sekitar Sebagai Sumber Belajar Anak." Refleksi Edukatika : Jurnal Ilmiah Kependidikan 8(1).

Fauzzia, Willma et al. 2018. "Penyuluhan Gerakan Go Green Sejak Dini Di SD Cipta Karya Bandung." Abdimas BSI 1(2): 355-60.

Heny Kusumawati. 2017. Lingkungan Sahabat Kita: Tema 8 Buku Tematik Terpadu Kurikulum 2013 (SD/MI Kelas V). Jakarta: Pusat Kurikulum dan Perbukuan, Balitbang, Kemendikbud.

Ipin, Arifin. 2017. "PEMBELAJARAN PENDIDIKAN LINGKUNGAN HIDUP BERORIENTASI 3R (REUSE, REDUCE AND RECYCLE) UNTUK MENINGKATKAN KREATIVITAS DAN SIKAP PEDULI LINGKUNGAN." Bio Educatio 2(2): 1-11.

Jufri; Jumarddin La Fua; Ratna Umi Nurlila. 2018. "PENDIDIKAN LINGKUNGAN DI SEKOLAH DASAR NENGERI 1 BARUGA KOTA KENDARI Jufri.” Jurnal Al-Ta'dib 11(2): 164-81.

Mardiani, Weyn. 2017. "Pelaksanaan Kegiatan Penghijauan Untuk Meningkatkan Kepedulian Terhadap Lingkunagn Di SDN 12 Pekan Baru." Jurnal IImu Pendidikan Sosial, sains, dan Humaniora 3(2): 269-97. http://ejournal.uinsuska.ac.id/index.php/suaraguru/article/view/3605. 
ISSN : $2620-4665$ (print)

ISSN : $2620-4673$ (online)

Website : http://jurnal.untan.ac.id/index.php/JPLP2KM

Muslicha, Anisa. 2016. "Metode Pengajaran Dalam Pendidikan Lingkungan Hidup Pada Siswa Sekolah Dasar (Studi Pada Sekolah Adiwiyata Di Dki Jakarta)." Jurnal Pendidikan 16(2): 110 26.

Nurhadi. 2009. Pusat Perbukuan Departemen Pendidikan Nasional Mengenal Lingkungan Sekitar. Pusat Perbukuan Departemen Pendidikan Nasional Tahun.

Pantiwati, Yuni. 2015. "Pemanfaatan Lingkungan Sekolah Sebagai Sumber Belajar Dalam Lesson Study Untuk Meningkatkan Metakognitif." Jurnal Bioedukatika 3(1): 27-32.

Rezkita, Shanta, and Kristi Wardani. 2018. "Pengintegrasian Pendidikan Lingkungan Hidup Membentuk Karakter Peduli Lingkungan Di Sekolah Dasar." TRIHAYU 4(2): 327-31.

Samri, Ferdinandus. 2016. "Membangun Siswa Sadar Lingkungan Melalui Integrasi Pendidikan Lingkungan Hidup Ke Dalam Pembelajaran IPS Di Sekolah Dasar Sebagai Alternatif Mewujudkan Sekolah Bersih Dan Hijau." In , 9-22.

Utaya; Sugeng, Susriyati Mahanal; 2009. Pendidikan Lingkungan Hidpu Untuk Sekolah Dasar Kelas VI. Pusat Penelitian Lingkungan Hidup Lembaga PEnelitian Universitas NEgeri Malang dan BAdan Lingkungan Hidup Provinsi JAwa Timur.

Wicaksono, Ratna Widyaningrum; Anggit Grahito. 2018. "PENANAMAN SIKAP PEDULI LINGKUNGAN DAN SIKAP ILMIAH SISWA SEKOLAH DASAR MELALUI SOSIALISASI PROGRAM SEKOLAH PEDULI DAN BERBUDAYA LINGKUNGAN." ADIWIDYA 2(1): 7381. 